\title{
Potential evolutionary body size reduction in a Malagasy primate (Propithecus verreauxi) in response to human size-selective hunting pressure
}

Alexis P. Sullivan ${ }^{1 *}$, Laurie R. Godfrey ${ }^{3}$, Richard R. Lawler ${ }^{4}$, Heritiana Randrianatoandro ${ }^{5}$, Laurie Eccles ${ }^{2}$, Brendan Culleton ${ }^{6}$, Timothy M. Ryan², George H. Perry ${ }^{1,2,7 *}$

Departments of ${ }^{1}$ Biology and ${ }^{2}$ Anthropology, Pennsylvania State University, State College, PA, USA

${ }^{3}$ Department of Anthropology, University of Massachusetts, Amherst, MA, USA

${ }^{4}$ Department of Sociology and Anthropology, James Madison University, Harrisonburg, VA, USA

${ }^{5}$ Department of Paleontology and Biological Anthropology, University of Antananarivo, Madagascar

${ }^{6}$ Institutes of Energy and the Environment, Pennsylvania State University, State College, PA, USA

${ }^{7}$ Huck Institutes of the Life Sciences, Pennsylvania State University, State College, PA, USA

*Addresses for correspondence: aps216@psu.edu; ghp3@psu.edu

\begin{abstract}
The Holocene arrival of humans on Madagascar precipitated major changes to the island's biodiversity. The now-extinct, endemic "subfossil" megafauna of Madagascar were likely hunted by the island's early human inhabitants. Perhaps in part due to preferential hunting of larger prey, no surviving species on Madagascar is larger than $10 \mathrm{~kg}$. Outside of Madagascar, size-selective hunting pressure has resulted in the phyletic dwarfism of many still-living species across a diversity of phyla. On Madagascar, some subfossil bones of extant lemurs are considerably larger than those of the modern members of their species, but relatively large distances between the subfossil localities and modern samples that have been compared to date makes it impossible to reject the possibility that these size differences more simply reflect pre-existing ecogeographic variation. Here, we used high-resolution 3D scan data to conduct comparative morphological analyses of subfossil and modern skeletal remains of one of the larger extant lemurs, Verreaux's sifakas (Propithecus verreauxi) from subfossil and modern sites $\sim 10 \mathrm{~km}$ adjacent: Taolambiby (bones dated to 725-560 - 1075-955 cal. years before present) and Beza Mahafaly Special Reserve, respectively. We found that the average subfossil sifaka bone $(n=12)$ is $9 \%$ and significantly larger than that of modern sifakas ( $n=31$ individuals; permutation test; $p=0.037$ ). When restricting the analysis to the single element and side with the largest representation in the subfossil sample ( $n=4$ right distal femora), the average subfossil bone is $10 \%$ larger $(p=0.046)$. While we cannot yet conclude whether this size difference reflects evolutionary change or an archaeological aggregation/taphonomic process, if this is a case of phyletic dwarfism in response to human sizeselective harvesting pressures then the estimated rate of evolutionary change is slightly higher than that previously calculated for other archaeological cases of this phenomenon.
\end{abstract}




\section{INTRODUCTION}

Intensive human behaviors including harvesting and predation, landscape modification, and translocation have effected non-human morphological evolution for at least tens of thousands of years [1]. For example, size-selective hunting pressure by humans has resulted in documented body size or feature reduction for many different non-human taxa [2,3], from aquatic invertebrates and vertebrates such as snails $[4,5]$ and salmon $[6,7]$ to terrestrial mammals like bighorn sheep $[8,9]$. For terrestrial taxa, assessments of body size diminution due to human hunting pressures have been largely restricted to ungulates [2,3]; no such process has yet been recorded for a non-human primate species.

The Malagasy megafauna were comprised of at least 28 large-bodied species from $11 \mathrm{~kg}$ to $\sim 650 \mathrm{~kg}$ in size [10], including at least 17 lemurs (primates), the largest of which had an estimated body mass of $\sim 160 \mathrm{~kg}[11,12]$. The timing of human arrival and permanent residence on Madagascar is uncertain $[13,14]$ but may extend to $\sim 10,500$ years BP or earlier [15-17]. There are reports of intentional human processing marks on lemur bones in southwest Madagascar dating to 2,300 years BP $[11,18,19]$. Human harvesting pressures, perhaps including preferential hunting of larger animals, have often been discussed as potential contributing factors in population declines and eventual extinctions of the island's megafauna [18,20-23]. Now, no surviving endemic terrestrial vertebrate species on Madagascar has a body mass larger than $10 \mathrm{~kg}$ [24].

On Madagascar, subfossil bones of still-living lemur species recovered from archaeological and paleontological contexts are often considerably larger than those of their modern counterparts [19,2527]. Godfrey et al. [26] noted that there are many subfossil sites in the southwest with Propithecus verreauxi bones that are both more robust and longer than modern Propithecus in the same region. Indeed Lamberton [28] had assigned a new species nomen, Propithecus verreauxoides, to subfossil specimens from Tsirave (south central Madagascar) because of its larger sizes for major skull measurements and long bone lengths relative to those of modern Propithecus verreauxi. Muldoon and Simons [25] reported a similar size disparity between Lepilemur subfossils from Ankilitelo and extant Lepilemur from the same general region, but they also noted that prehistoric-extant size differences could simply reflect ecogeographic variation rather than recent body size evolution.

For our present study, we identified an opportunity to investigate a potential case of nonhuman primate phyletic dwarfism due to human hunting pressures without the complicating factor of large geographic distance between where the compared subfossil and modern individuals lived. Specifically, we report the results from a morphological analysis of Verreaux's sifaka (Propithecus verreauxi) postcranial skeletal remains from the subfossil Taolambiby site and the Beza Mahafaly Special Reserve, located $\sim 10 \mathrm{~km}$ apart (Figure 1), to test the hypothesis that $P$. verreauxi body size decreased following the earliest appearance of cut-marked bones.

\section{MATERIALS AND METHODS}

Osteological Collections. We surveyed the osteological collections from two sites in southwestern Madagascar in an attempt to characterize a body size diminution in local Propithecus verreauxi over time. $P$. verreauxi has an adult body mass ranging from $\sim 2.5-3.5 \mathrm{~kg}[29,30]$, and has historically been hunted by humans across multiple parts of its range [31-33]. Specifically, more than $250 P$. verreauxi skeletal and craniodental elements were surface-collected from along the Taolambiby village river wash by Alan Walker in 1966 [17,19] (Figure 1). This Taolambiby collection was donated to the Anthropological Primate Collection at the University of Massachusetts, Amherst (UM-TAO). Cut marks, chop marks, and/or spiral fractures indicative of human processing were identified on $62 \%$ of the $P$. verreauxi elements [19]. The Taolambiby subfossil material is fragmentary; from the larger collection available to us there were a total of 15 elements that could be identified confidently as adult $P$. verreauxi femora and humeri that we included in our study. 
Immediately adjacent to this subfossil site/collection is the Beza Mahafaly Special Reserve (BMSR; Figure 1), which is home to an extant sifaka population that has been monitored and studied since 1984 [34]. In the first 25 years of BMSR collection and management of sifaka long-term data, 718 individuals have been captured, measured, and marked; now there are $>900$ individuals [34]. Since 1985, researchers have also been collecting and labeling faunal skeletal remains discovered in the course of observation or survey [35]. The resulting Beza Mahafaly Osteological Collection (BMOC) is comprised of skeletal elements from all four extent lemur species living in the area, along with invasive wildcats. $P$. verreauxi was represented in this collection by the remains of 31 adult individuals at the time of our data collection (see Supplementary Table 1 for full list of individuals). 

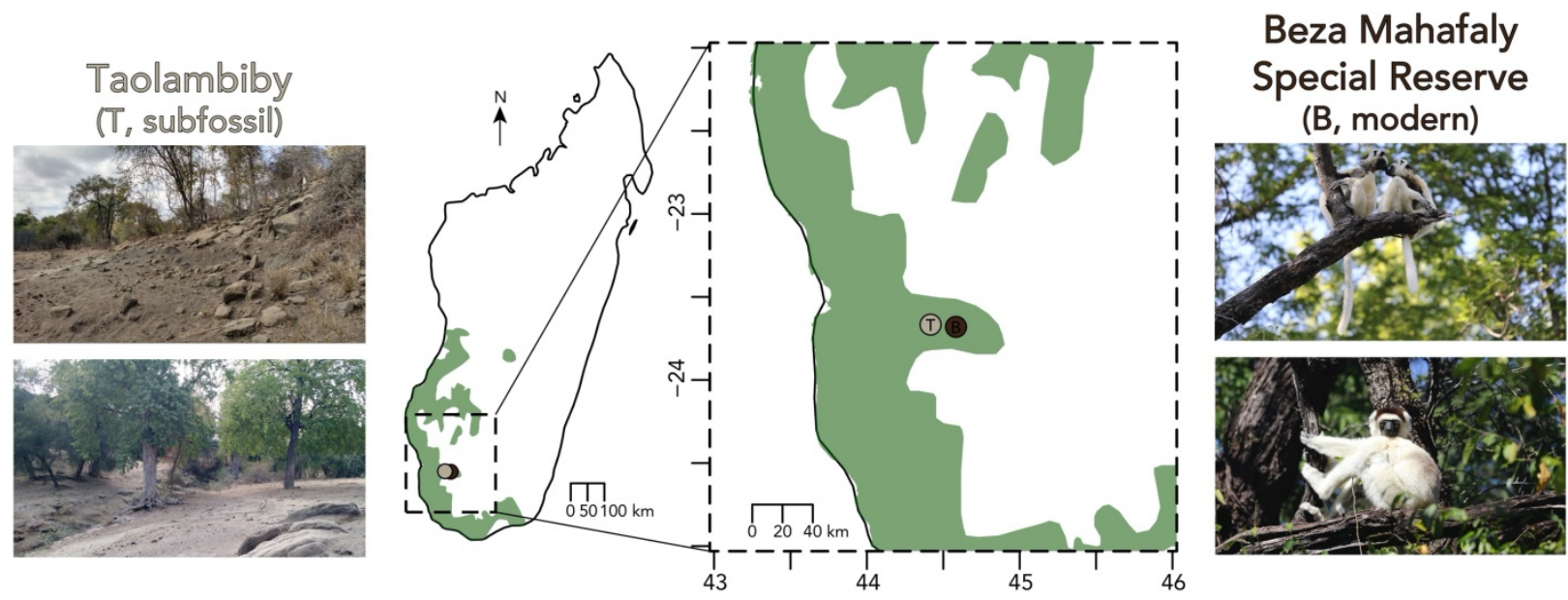

Figure 1: Propithecus verreauxi osteological collection sites. Verreaux's sifaka range data in green from IUCN Red List database [species 18354], last updated 2014. Subfossil osteological materials were collected from Taolambiby (tan dot), and modern remains from the Beza Mahafaly Special Reserve (brown dot). 
Data Collection. We focused on femora and humeri because there is a strong positive correlation between measurements from these long bones and overall body size in Propithecus lemurs [36]. Juvenile specimens, identified by the presence of an epiphyseal line or an unfused epiphysis [37], were excluded from our analysis. Of the modern BMOC adults ( $n=31$ total), sex was known for eight individuals ( $26 \% ; n=4$ males, $n=4$ females) based on the association of their remains with collars and/or other identifying features (see Supplementary Table 1). Since sifakas are not sexually dimorphic [29,3840], male and female adults are expected to have approximately similar body sizes and sex was not included as a variable in our analyses.

We collected 3D surface data from every adult $P$. verreauxi long bone that was available in each collection, fragmented or whole, right or left, with a portable Artec Space Spider (Artec 3D, Luxembourg; Figure 2; Table 1). All data collection at the Beza Mahafaly Special Reserve was approved by the Madagascar National Parks organization. The Spider scanner records high-resolution geometry and texture data at up to $0.1 \mathrm{~mm}$ resolution and 3D point accuracy up to $0.5 \mathrm{~mm}$. Each of the 106 adult skeletal elements from these collections ( $n=94$ modern, 15 subfossil) was affixed to a turntable, and the Artec Space Spider was used to collect between 4-8 scans from multiple angles to capture the entirety of the bone. Linear caliper measurements ( $n=5$ for humeri, 6 for femora; Table 1) were also collected from every bone (see Supplementary Table 2).

3D Surface Scan Post-Processing. The surface scan data were post-processed with Artec Studio 11 software to form 3D models for each element. Specifically, scans were first individually cleaned with the "Eraser" function to remove the turntable and other background noise. The multiple scans of the same element were then aligned to one another with at least three points of common geometry. The aligned scan data were then registered "Global Registration" with settings for $50 \mathrm{~mm}$ minimal distance and 5000 iterations) and fused ("Fusion": default "Outlier Removal" and "Sharp Fusion" settings with "Watertight" $0.3 \mathrm{~mm}$ resolution). 3D meshes of each element were then exported and individually measured as indicated in Table 1 and Figure 2 with Avizo 9.4 software (see Supplementary Table 3). We measured maximum length, midshaft diameters and circumferences for all whole femora, as well as femoral head heights, widths, and surface areas, bi-epicondylar breadth, and condylar widths and surface areas when available $[36,37,41]$. We measured maximum length and midshaft diameters for all whole humeri, as well as humeral head diameters, widths, and surface areas, and bi-epicondylar breadth when available $[36,37,41]$. Surface areas were determined by isolating the osteological region of interest from the rest of the bone, then using the Materials Surface Area Statistics tool available in Avizo. All 3D models are available on MorphoSource ("Sullivan/Perry Lab Propithecus verreauxi Surface Scans" Project ID 698). 
bioRxiv preprint doi: https://doi.org/10.1101/2020.03.23.004234; this version posted March 26, 2020. The copyright holder for this preprint (which was not certified by peer review) is the author/funder, who has granted bioRxiv a license to display the preprint in perpetuity. It is made available under aCC-BY-NC-ND 4.0 International license.

A Photo of elements Artec Space Spider scanning

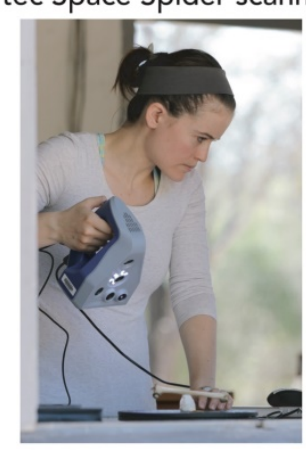

Artec Studio 3D model

Avizo export measuring
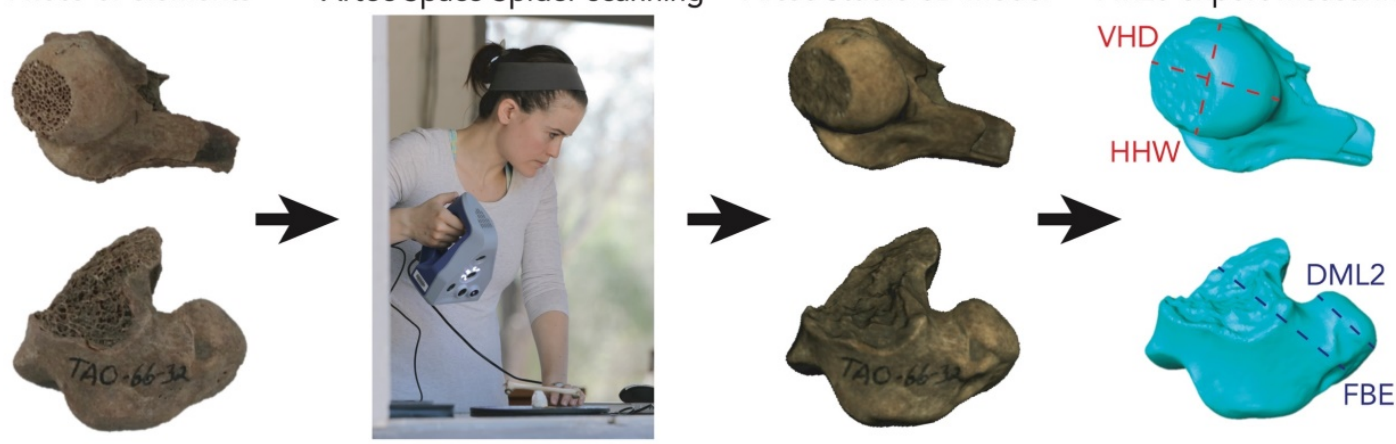

C

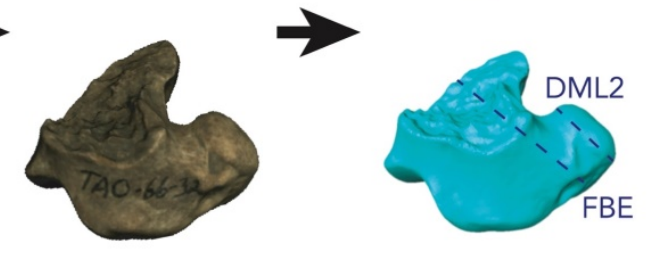

B

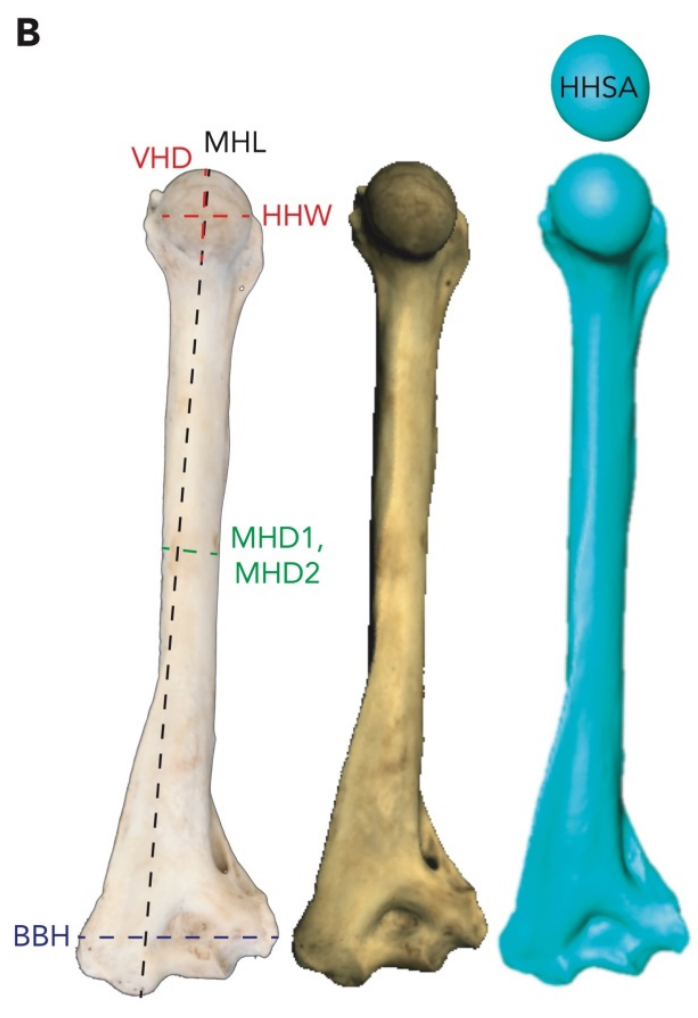

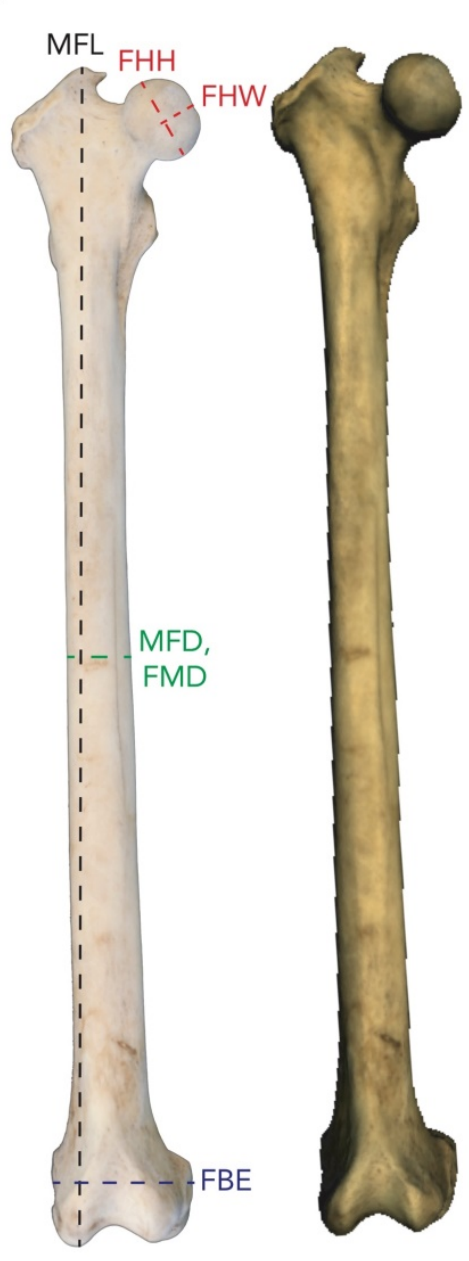

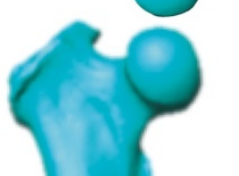

Figure 2: Examples of osteological elements of $\boldsymbol{P}$. verreauxi and the measurements collected for this study. Descriptions of each measurement are available in Table 1. (A) Two subfossil elements from Taolambiby. The humeral head (UM-TAO-66-2) was radiocarbon dated to 1000 BP and the distal femur (UM-TAO-66-32) was dated to 740 BP. Diagram of measurements collected from (B) humeri and (C) femora (distal condyle widths not pictured; example humerus and femur from BMOC-020). 
Table 1: Morphometric caliper and 3D surface scan measurement descriptions.

\begin{tabular}{|c|c|c|c|c|c|c|c|c|c|c|}
\hline & & & & & lumber & of Elen & ients $M$ & easure & & \\
\hline & & & & 3D S & anner & & & Radial & Caliper & \\
\hline & & & Moc & ern & Subf & ssil & Moc & ern & Subf & ssil \\
\hline & Measurement & Measurement Description & Right & Left & Right & Left & Right & Left & Right & Left \\
\hline & $\mathrm{MHL}$ & $\begin{array}{l}\text { Maximum length measured between top of } \\
\text { humeral head and most distant point on } \\
\text { distal humerus }\end{array}$ & 18 & 22 & 0 & 0 & 16 & 19 & 0 & 0 \\
\hline & MHD1 & $\begin{array}{l}\text { Maximum midshaft humeral diameter, } \\
\text { measured just below deltoid }\end{array}$ & 23 & 23 & 0 & 0 & 23 & 20 & 0 & 0 \\
\hline & $\begin{array}{c}\text { MHD2 } \\
\text { [3D only] }\end{array}$ & $\begin{array}{l}\text { Minimum midshaft humeral diameter, } \\
\text { measured just below deltoid }\end{array}$ & 23 & 23 & 0 & 0 & NA & NA & NA & NA \\
\hline$\frac{\mathrm{L}}{\mathrm{d}}$ & VHD & $\begin{array}{l}\text { Vertical head diameter, superoinferior } \\
\text { diameter }\end{array}$ & 21 & 23 & 1 & 0 & 20 & 20 & 1 & 0 \\
\hline & $\mathrm{HHW}$ & $\begin{array}{l}\text { Humeral head width, external transverse } \\
\text { mediolateral diameter }\end{array}$ & 21 & 23 & 1 & 0 & 20 & 20 & 1 & 0 \\
\hline & $\mathrm{BBH}$ & $\begin{array}{l}\text { Biepicondylar breadth, greatest distance } \\
\text { between medial and lateral epicondyles, } \\
\text { parallel to humeral shaft }\end{array}$ & 22 & 23 & 0 & 0 & 21 & 20 & 0 & 0 \\
\hline & $\begin{array}{l}\text { HHSA [3D } \\
\text { only] }\end{array}$ & $\begin{array}{l}\text { Avizo-calculated humeral head surface } \\
\text { area }\end{array}$ & 21 & 23 & 1 & 0 & NA & NA & NA & NA \\
\hline & MFL & $\begin{array}{l}\text { Maximum length that can be measured } \\
\text { between the top of the greater trochanter } \\
\text { and bottom of the most distal condyle }\end{array}$ & 20 & 19 & 0 & 0 & 21 & 18 & 0 & 0 \\
\hline & MFD & $\begin{array}{l}\text { Anteroposterior (sagittal) midshaft } \\
\text { diameter }\end{array}$ & 23 & 24 & 0 & 0 & 24 & 24 & 0 & 0 \\
\hline & $\begin{array}{c}\text { FMD } \\
{[3 D \text { only }]}\end{array}$ & $\begin{array}{l}\text { Mediolateral (transverse) midshaft } \\
\text { diameter }\end{array}$ & 23 & 24 & 0 & 0 & NA & NA & NA & NA \\
\hline & $\begin{array}{c}\text { MFC } \\
\text { [caliper only] }\end{array}$ & Midshaft circumference & NA & NA & NA & NA & 23 & 24 & 0 & 0 \\
\hline & $\mathrm{FHH}$ & $\begin{array}{l}\text { Femoral head height, superoinferior } \\
\text { diameter }\end{array}$ & 24 & 20 & 2 & 2 & 24 & 20 & 2 & 2 \\
\hline 气 & FHW & $\begin{array}{l}\text { Femoral head width, anteroposterior } \\
\text { diameter }\end{array}$ & 24 & 20 & 2 & 2 & 24 & 20 & 2 & 2 \\
\hline & FBE & $\begin{array}{l}\text { Femoral biepicondylar breadth, distance } \\
\text { between medial-most and lateral-most } \\
\text { points on epicondyles }\end{array}$ & 23 & 21 & 2 & 1 & 23 & 21 & 1 & 2 \\
\hline & $\begin{array}{l}\text { DML1 } \\
\text { [3D only] }\end{array}$ & Width of medial distal condyle & 23 & 21 & 0 & 2 & NA & NA & NA & NA \\
\hline & $\begin{array}{c}\text { DML2 } \\
\text { [3D only] }\end{array}$ & Width of lateral distal condyle & 23 & 21 & 4 & 3 & NA & NA & NA & NA \\
\hline & $\begin{array}{c}\text { FHSA } \\
{[3 D \text { only] }}\end{array}$ & Avizo-calculated femoral head surface area & 24 & 20 & 2 & 2 & NA & NA & NA & NA \\
\hline & $\begin{array}{c}\text { DSA } \\
{[3 \mathrm{D} \text { only] }}\end{array}$ & Avizo-calculated condylar surface area & 23 & 21 & 0 & 1 & NA & NA & NA & NA \\
\hline
\end{tabular}

Note: Unless specified, each measurement was collected with both linear calipers and 3D scan data. 
AMS Radiocarbon Dating. It was important to establish the antiquity of each subfossil element included in our analysis with radiocarbon ${ }^{14} \mathrm{C}$ dating methods. Of 18 Taolambiby $P$. verreauxi skeletal elements dated in a prior study, one (5.6\%) was modern and the remaining $17(94.4 \%)$ ranged from 605 to 1185 cal BP [42, Supplementary Table 3]. Of those 17 previously dated, non-modern specimens, one was a proximal humerus and seven were femora. The humeral fragment and five of the femoral fragments were sufficiently intact for us to obtain at least one size measurement per bone (Table 2).

Nine additional (not previously radiocarbon dated) adult $P$. verreauxi femora from Taolambiby were also available for possible inclusion in our analysis. For each of these specimens, we first collected all measurements and 3D surface scan data before sampling 200-500 mg from the subfossil skeletal remains for AMS radiocarbon ${ }^{14} \mathrm{C}$ dating and stable isotope analyses at the Penn State University Human Paleoecology and Isotope Geochemistry Laboratory. The bone samples were scraped with blades to remove adhering material and clipped into small pieces. As a precaution, we removed possible conservants and adhesives by sonicating the scraped bone samples in washes of ACS-grade methanol, acetone, and dichloromethane for 20 minutes each at room temperature. Bone collagen was extracted and purified after sonication. Samples were demineralized for $1-3$ days in $0.5 \mathrm{~N}$ hydrochloric acid at $5^{\circ} \mathrm{C}$.

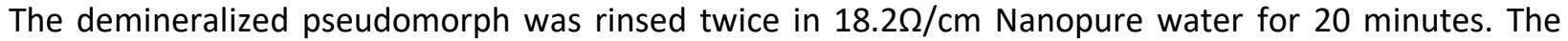
pseudomorph was gelatinized for 10 hours at $60^{\circ} \mathrm{C}$ in 0.01 Normal hydrochloric acid. The resulting gel was then lyophilized and weighed to determine percent yield as a first evaluation of the degree of bone collagen preservation.

In this case the collagen samples were relatively poorly preserved and so they were pretreated using a modified XAD process $[43,44]$ after demineralization and gelatinization. The gelatin was hydrolyzed in $1.5 \mathrm{~mL}$ of 6 Normal hydrochloric acid for 24 hours at $110^{\circ} \mathrm{C}$. Supelco ENVI-Chrome P SPE (Solid Phase Extraction) columns were fitted with a Millex HV PVDF $0.45 \mu \mathrm{m}$ filter unit, and both were equilibrated with $50 \mathrm{~mL}$ of 6 Normal hydrochloric acid. The $1.5 \mathrm{~mL}$ sample hydrolyzate was pipetted into the SPE column and driven through with a syringe and an additional $10 \mathrm{~mL}$ of $6 \mathrm{~N}$ hydrochloric acid dropwise into a prepared $20 \mathrm{~mm}$ culture tube. The hydrolyzate (now bone collagen amino acids) was dried into a viscous syrup by passing UHP nitrogen gas over the heated $\left(50^{\circ} \mathrm{C}\right)$ sample for about 8 hours.

The XAD amino acids were analyzed for carbon and nitrogen concentrations and stable isotope ratios at the Yale Analytical and Stable Isotope Center with a Costech elemental analyzer (ECS 4010) and Thermo DeltaPlus isotope ratio mass spectrometer. Sample quality was evaluated by $\% \mathrm{C}, \% \mathrm{~N}$, and the $\mathrm{C}: \mathrm{N}$ ratio before $\mathrm{AMS}{ }^{14} \mathrm{C}$ dating. Good quality amino acid samples were then weighed (3.5-4.5 mg) into 8 " quartz tubes, with $60 \mathrm{mg} \mathrm{CuO}$ and a $\sim 2 \mathrm{~mm}$ snip of $1 \mathrm{~mm}$ diameter $99.9 \%$ silver wire, then sealed under vacuum and combusted at $800^{\circ} \mathrm{C}$ for 3 hours.

The resulting $\mathrm{CO}_{2}$ was reduced to graphite at $550^{\circ} \mathrm{C}$ using UHP hydrogen gas and an iron catalyst, with the reaction water removed by magnesium perchlorate $\left(\mathrm{Mg}\left(\mathrm{ClO}_{4}\right)_{2}\right)$. Graphite samples were pressed into targets and loaded onto a target wheel with oxalic acid (OXII) primary standards, known age bone secondaries and ${ }^{14} \mathrm{C}$ free Pleistocene whale blank, and measured on a modified NEC $1.5 \mathrm{SDH}-1500 \mathrm{kV}$ compact accelerator mass spectrometer housed in the Penn State Earth and Environmental Sustainability Laboratories. Three subfossil elements, UM-TAO-66-22, UM-TAO-66-28, and an unaccessioned femoral head, had insufficient remaining collagen for either isotopic or radiocarbon analysis, and thus were not included in our subsequent morphological analyses. Two samples were run on the AMS but not assigned PSUAMS lab codes, and should be considered provisional. $\mathrm{C}$ and $\mathrm{N}$ abundance and isotope ratios were unavailable for UM-TAO-66-31, and C:N ratio for UM-TAO-66-32 was 3.64, at the limits of the acceptable range. AMS radiocarbon results from this study and previous dates by Crowley and Godrey [42] were calibrated with OxCal v. 4.3.2 [45] using the SHCal13 southern hemisphere curve [46] and are presented in Table 2. 
Table 2: Subfossil $\boldsymbol{P}$. verreauxi elements that were included in this study and their corresponding radiocarbon dates.

\begin{tabular}{|c|c|c|c|c|c|c|}
\hline Sample ID & $\begin{array}{l}\text { Element } \\
\text { (Side, End) }\end{array}$ & $\begin{array}{l}\text { Human Processing } \\
\text { Mark(s) }\end{array}$ & ${ }^{14} \mathrm{C}$ Lab ID & $\begin{array}{l}\text { Conventional } \\
{ }^{14} \mathrm{C} \text { Age (BP) }\end{array}$ & $\begin{array}{l}\text { Calibrated } 95.4 \% \\
\mathrm{Cl} \text { (cal. BP) }\end{array}$ & Reference \\
\hline UM-TAO-66-26 & Femur $(R, D)$ & Chop & PSUAMS-2480 & $1010 \pm 15$ & $925-800$ & This study \\
\hline UM-TAO-66-29 & Femur $(\mathrm{R}, \mathrm{D})$ & Chop & PSUAMS-2479 & $865 \pm 20$ & $770-680$ & This study \\
\hline UM-TAO-66-32 & Femur $(R, D)$ & Chop & $\mathrm{N} / \mathrm{A}^{*}$ & $740 \pm 40$ & $725-560$ & This study \\
\hline UM-TAO-66-33 & Femur $(\mathrm{R}, \mathrm{D})$ & Chop & PSUAMS-2477 & $975 \pm 20$ & $920-790$ & This study \\
\hline UM-TAO-66-31 & Femur (L, D) & Chop & $\mathrm{N} / \mathrm{A}^{*}$ & $850 \pm 35$ & $775-670$ & This study \\
\hline UM-TAO-66-34 & Femur (L, D) & $\begin{array}{l}\text { Chop, slice } \\
\text { through condyles }\end{array}$ & PSUAMS-2476 & $840 \pm 20$ & $740-675$ & This study \\
\hline UM-TAO-66-2 & $\begin{array}{l}\text { Humerus } \\
(\mathrm{R}, \mathrm{P})\end{array}$ & Chop, cut marks & CAMS-147111 & $1035 \pm 25$ & $960-800$ & {$[42]$} \\
\hline UM-TAO-66-21 & Femur $(R, P)$ & Chop & CAMS-147036 & $1130 \pm 30$ & $1060-930$ & {$[42]$} \\
\hline UM-TAO-66-23 & Femur $(L, P)$ & Chop & CAMS-147628 & $1055 \pm 30$ & $965-805$ & [42] \\
\hline UM-TAO-66-24 & Femur $(L, P)$ & Chop & CAMS-147114 & $940 \pm 40$ & $915-730$ & [42] \\
\hline UM-TAO-66-25 & Femur $(R, P)$ & Chop & CAMS-147113 & $915 \pm 35$ & $905-685$ & [42] \\
\hline UM-TAO-66-30 & Femur (L, D) & Chop & CAMS-147332 & $1165 \pm 30$ & $1075-955$ & [42] \\
\hline
\end{tabular}

*UM-TAO-66-31 and -32 were not assigned PSUAMS-\# because there is no EA-IRMS data (-31) or poor C:N ratio (-32).

Correlations Between 3D Scan and Caliper Measurements. We directly compared the equivalent raw caliper and 3D scan measurements to each other as an accuracy check for each measurement technique. For every available measurement category (MFL, MFD, FHH, FHW, FBE; MHL, MHD1, VHD, $\mathrm{HHW}, \mathrm{BBH}$ ) we calculated the percent difference between the corresponding caliper measurement and 3D scan measurement taken for each individual skeletal element:

$$
\% \text { Difference }=\left(\frac{\text { Caliper }-3 D}{(\text { Caliper }+3 D) / 2}\right) * 100
$$

We determined that, on average, the caliper measurements were $0.68 \%$ smaller than the equivalent 3D measurements for the modern skeletal remains and $1.20 \%$ larger for the subfossil elements (Supplemental Table 4; see Supplemental Table 5 for all caliper versus 3D measurement comparisons). This difference is likely due to difficulties in identifying measurement landmarks with the calipers on the more broken subfossil materials.

With the advantages of increased maximum/minimum measurement accuracy and surface area calculation tools, more 3D model measurements were able to be collected from the fragmented modern and subfossil materials relative to those with the caliper: 10 femoral 3D measurements versus 6 with caliper, and 7 humeral 3D versus 5 with caliper. For some bones, 3D digital measurement only was possible. Therefore, all results presented here are based on the 3D model measurements to increase the number of specimens included in the analyses.

3D Surface Scan Measurement Analyses. The limited number of 3D surface scan measurements that could be taken on each subfossil bone precluded our ability to directly estimate individual body sizes. Therefore, we compared the individual bone measurements to each other. To do so, for each measurement we first calculated the geometric mean (geoMean, GM; [47]) from all available modern individuals for that measurement (Table 3, Step A). As an example, the geoMean of the modern right femoral head height (FHH) from the 3D surface scan data was $12.37 \mathrm{~mm}$. These geoMeans were then used to calculate a relative fold change $(F C)$ value for each individual modern and subfossil skeletal element (Table 3, Step B). For example, the FHH measurements for modern BMOC-001 was $12.21 \mathrm{~mm}$ and for subfossil UM-TAO-66-25 was $12.90 \mathrm{~mm}$. The FC for each of these individuals was calculated from the $12.37 \mathrm{~mm}$ GM: -0.01 and 0.04 , respectively. 
Then, all of the FC values available for each separate sided bone $(z)$ were arithmetically averaged ( $A$; Table 3, Step $\mathrm{C}$ ). Finally, for each modern individual an aggregate score $(A S)$ was calculated as the mean of the averages from each element available for that individual (up to four; i.e. right and left, humeri and femora) (Table 3, Step D). For the subfossil remains, the per-bone average FC value is the same as the individual $A S$, because potential individual-associations among any of the different subfossil elements are unknown.

Table 3: Measurement analysis calculations and examples.

\begin{tabular}{|c|c|c|c|}
\hline \multicolumn{2}{|c|}{ Step } & Variable Description(s) & Formula \\
\hline A. & $\begin{array}{l}\text { geoMean of each measurement, } \\
\text { calculated from the modern samples }\end{array}$ & $\begin{array}{l}G M_{x} \text { where } x=\text { measurement type } \\
\text { (ex: } \mathrm{FHH})\end{array}$ & $\left(\prod^{n} G M_{x_{i}}\right)^{\frac{1}{n}}=\sqrt[n]{x_{y 1} \cdot x_{y 2} \cdot \ldots \cdot x_{y n}}$ \\
\hline B. & $\begin{array}{l}\text { For each individual bone and element, } \\
\text { fold change from geoMean }\end{array}$ & $\begin{array}{l}F C_{x_{y}} \text { where } y=\text { individual } \\
\text { (ex: BMOC001) }\end{array}$ & $F C_{x_{y 1}}=\left(\frac{x_{y 1}}{G M_{x}}\right)-1$ \\
\hline C. & $\begin{array}{l}\text { Average fold change for each skeletal } \\
\text { element }\end{array}$ & $\begin{array}{l}A_{z 1_{y 1}} \text { where } z=\text { sided element } \\
\text { (ex: right femur) }\end{array}$ & $A_{z 1_{y 1}}=\frac{F C_{x 1_{y 1}}+\cdots+F C_{x n_{y 1}}}{n}$ \\
\hline D. & $\begin{array}{l}\text { Aggregate per-individual fold-change } \\
\text { scores from all available skeletal } \\
\text { elements for that individual }\end{array}$ & $A S_{y 1}$ & $A S_{y 1}=\frac{A_{z 1_{y 1}}+A_{z 2_{y 1}}+\cdots+A_{z n_{y 1}}}{n}$ \\
\hline
\end{tabular}

As an example, modern individual BMOC-001 had two complete femora and humeri, and all measurements were collected. The fold change difference was calculated for each of BMOC-001's right femoral measurements, and the average of those fold changes was calculated to be -0.005 . A negative average fold change $(A)$ indicates that the right femoral bones of BMOC-001 were slightly smaller than the right femoral geoMean of the modern population of Beza Mahafaly lemurs. Each of the $A$ values for BMOC-001's two femora and humeri were averaged for a final aggregate score (AS). A positive AS of 0.003 indicates that the bones of BMOC-001 were slightly larger than the average AS of the modern population of Beza Mahafaly lemurs. Subfossil element UM-TAO-66-21 had only three measurements taken, and the $A S$ of the fold changes for those three measurements was 0.142 , indicating an element larger than BMOC-001 as well as the average AS of the modern population.

We conducted two randomized subsampling permutation analyses to determine where the subfossil dataset's average aggregate score would fall against distributions generated from the same amount of modern measurement data. One permutation analysis was conducted with the full $n=12$ subfossil elements treated as separate individuals and the other by analyzing only the skeletal element and side with the best representation in the dataset, or the minimum number of individuals (right distal femur; $M N I n=4)$. A random subset of the modern data was partitioned to mimic those available for the subfossil individuals. In the case of the MNI group, this meant two right femoral FBE measurements and four DML2 measurements. The $G M, F C$, and $A S$ were calculated from this subset of modern measurements, as described above, and then the entire subset procedure was repeated 10,000 times for comparison with the average aggregate scores of the respective subfossil groupings. All code developed and used for this project is available in the GitHub repository https://github.com/AlexisPSullivan/Sifaka.

\section{RESULTS}

We compared long bone measurements as a proxy for body size between Propithecus verreauxi skeletal remains from the Taolambiby subfossil site (725-560 - 1075-955 calibrated $95.4 \% \mathrm{Cl}$ years before present) to those collected from modern individuals of the same species at the nearby Beza Mahafaly Special Reserve ( $<10 \mathrm{~km}$ from Taolambiby) to evaluate whether this population experienced body size diminution in the recent past. If so, then this result would be consistent with the hypothesis that human 
size-selective hunting pressures may have driven phenotypic evolutionary change in Madagascar's surviving fauna.

When comparing subfossil and modern specimens, we treated the entire scanned collection ( $\mathrm{N}$ $=12$ ) as our maximum number of individuals (MAX, Figure $3 A$ ), and the four subfossil right distal femoral fragments (UM-TAO-66-26, -29, -32, -33) as our minimum number of individuals (MNI, Figure 4A). We calculated the fold-change difference between the measurements of each bone (subfossil) or individual (modern) and the geoMean of the modern population (Figures 3B; Figure 4B). 
bioRxiv preprint doi: https://doi.org/10.1101/2020.03.23.004234; this version posted March 26, 2020. The copyright holder for this preprint (which was not certified by peer review) is the author/funder, who has granted bioRxiv a license to display the preprint in perpetuity. It is made available under aCC-BY-NC-ND 4.0 International license.

A 3D Surface Scan Models of All Subfossils (UM-TAO-66-\#\#)

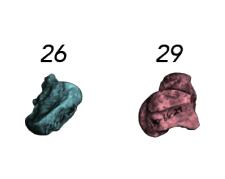

B Right Femora

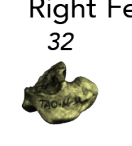

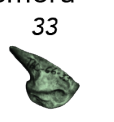
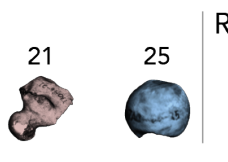

Right Humerus
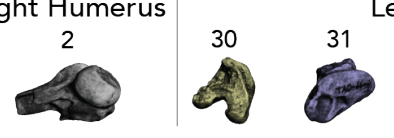

Left Femora
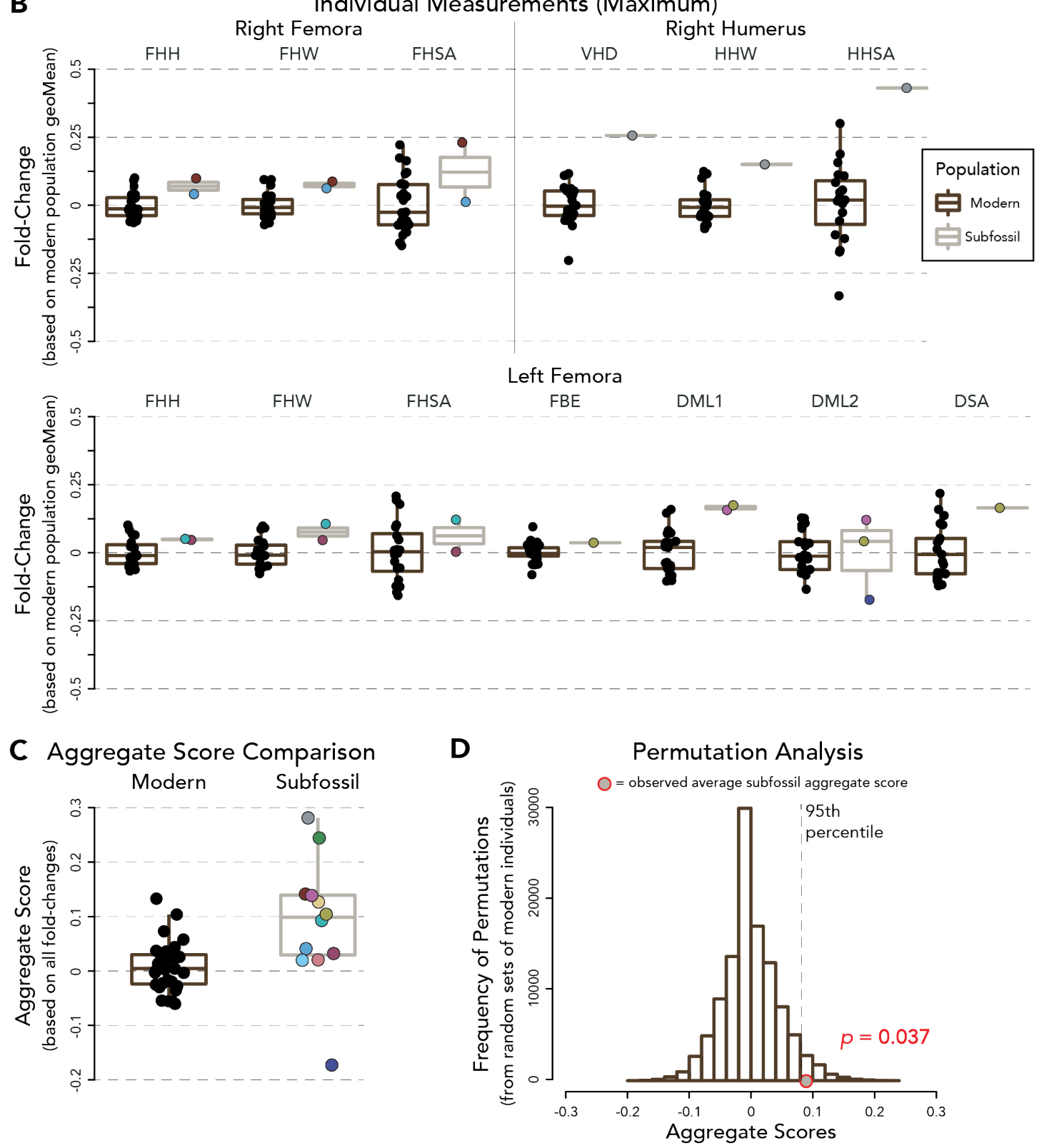

Figure 3: Our comparative morphological results for the maximum number of subfossil individuals (MAX). A: Each subfossil sample is separately colored to demonstrate progression through our pipeline. B: Fold-changes for both modern and subfossil 3D surface scan measurements for which there any subfossil data points are available. See Table 1 for the description of individual measurements. C. Aggregate scores for each subfossil skeletal element and modern individual. D. Permutation analysis depicting the distribution of average aggregate scores calculated from 10,000 subsets of modern measurements randomly selected to match the sample sizes of the MAX subfossil dataset. The actual average aggregate value $(0.089)$ for the MAX subfossil sample is shown with a red circle. The indicated empirical $p$-value $(p=0.037)$ represents the proportion of permuted modern values equal or greater to the actual subfossil value. 
A 3D Surface Scan Models of Subfossil MNI UM-TAO- UM-TAO- UM-TAO- UM-TAO66-26 $66-29$
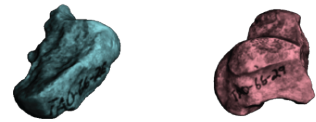

66-32

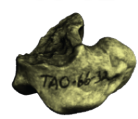
66-33

B Individual Right Femoral Measurements

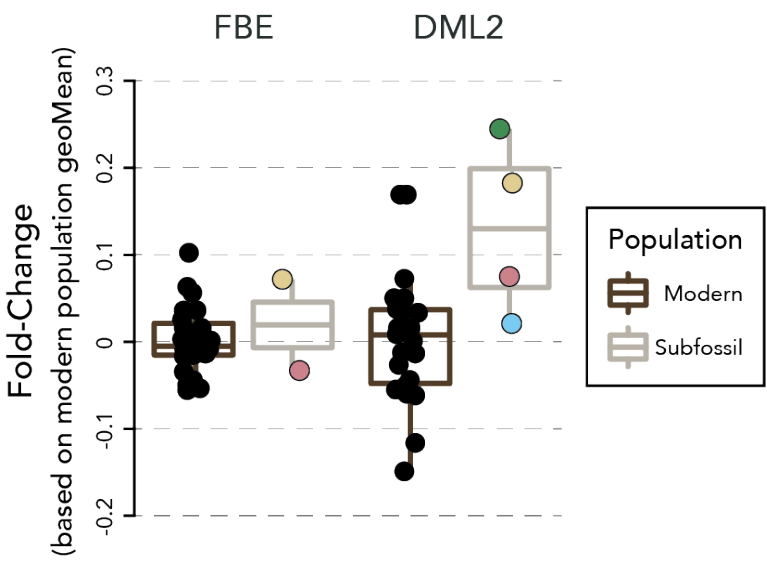

\section{MNI Aggregate Score Comparison}

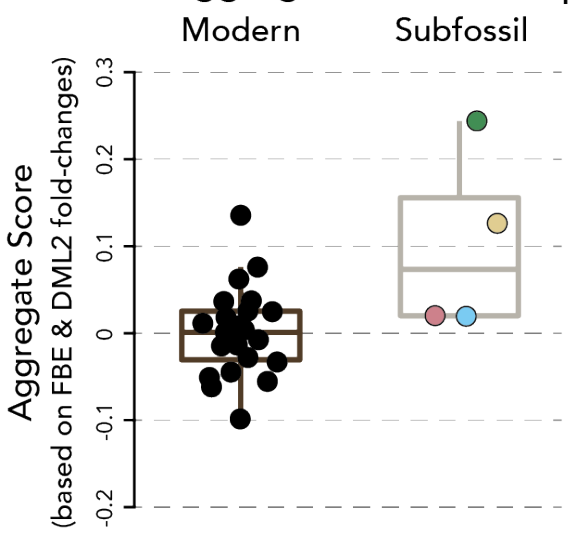

D

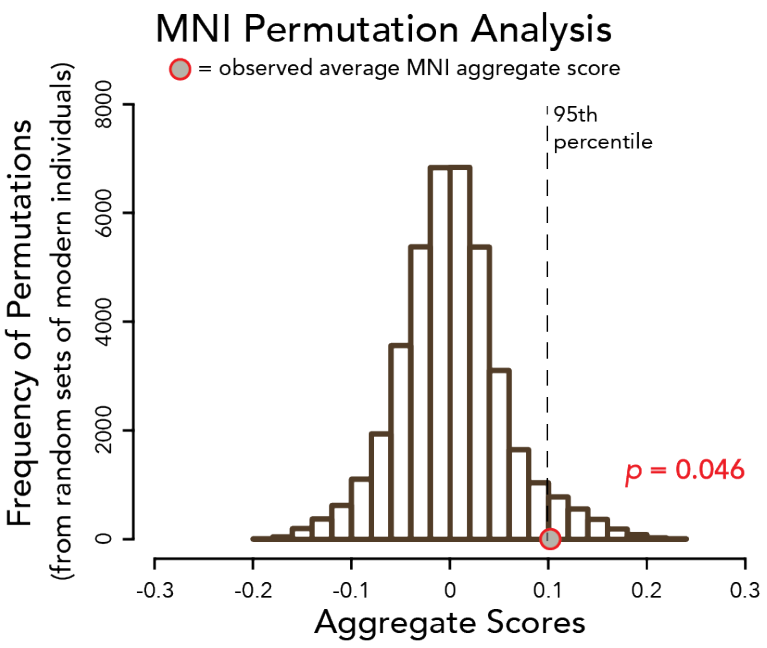

Figure 4: Comparative morphological results for the minimum number of subfossil individuals (MNI). A: Each subfossil sample is separately colored to demonstrate progression through our pipeline. B: Foldchanges for those modern and subfossil 3D surface scan measurements for which there are any subfossil data points. See Table 1 for the description of individual measurements. C. Aggregate scores for each subfossil and modern individual. D. Permutation analysis depicting the distribution of average aggregate scores calculated from 10,000 subsets of modern measurements randomly selected to match the sample sizes of the MNI subfossil dataset. The actual average aggregate value (0.103) for the MNI subfossil sample is shown with a red circle. The indicated empirical $p$-value $(p=0.046)$ represents the proportion of permuted modern values equal or greater to the actual subfossil value. 
As described in the Methods, each of the fold-change averages was arithmetically averaged for each individual across every element available for that individual to create an aggregate score (AS) that we used to directly compare modern and subfossil individuals to each other (Figure 3C; Figure 4C; Supplementary Table 6). The mean aggregate score for all subfossil elements (MAX; 0.089 \pm 0.117 ) is significantly greater than that for the modern individuals $(0.009 \pm 0.045$; Welch two-sample t-test; $\mathrm{p}=0.039$; Figure $3 \mathrm{C}$ ). With only four right distal subfossil femora, the mean aggregate score for subfossil $\mathrm{MNI}(0.103 \pm 0.107)$ was not significantly different than that for the modern individuals with a t-test (0.002 $\pm 0.051 ; p=0.153$; Figure 4C).

We further used a permutation scheme to test the null hypothesis of no size difference between the modern and subfossil populations. Specifically, for each of the MAX and MNI comparisons we selected a random subset of the modern data to match the number of specimens and measurement types of the subfossil dataset, computed the aggregate score for that permuted modern dataset, and repeated that process 10,000 times. To compute empirical p-values, the observed subfossil aggregate scores were compared to the distributions of permuted results, with significant differences for both MAX (Figure 3D; $p=0.037$ ) and MNI (Figure 4D; $p=0.046$ ).

\section{DISCUSSION}

This work represents the first systematic assessment of the potential evolutionary effects of human sizeselective hunting pressures on body size in a non-human primate. Using skeletal remains of both modern and subfossil $P$. verreauxi individuals from the same region of Southwest Madagascar and a high-resolution 3D surface scanning-based approach, we found that archaeological (725-560 - 1075-955 cal. years before present) body size-associated skeletal measurements were significantly larger than those of the modern sample.

While this result is consistent with the hypothesis of recent phyletic dwarfism in response to size-selective hunting pressures by humans, our finding alone does not necessarily demonstrate a history of adaptive evolution for smaller body sizes in this population. As an alternative explanation, the archaeological sample could be biased by assemblage and/or taphonomic processes [48]. For example, if past people were preferentially hunting larger sifaka with projectiles such as slingshots or blowguns $[49,50]$, then individuals who ended up in the archaeological sample may have been larger than the average for the overall population at the time. Additionally, larger bones may have been more likely to be preserved in the Taolambiby wash. The combination of expanded archaeological sampling and evolutionary genomic analyses with knowledge of $P$. verreauxi body size-associated alleles may ultimately be necessary to distinguish between the evolutionary vs. assemblage/taphonomic scenarios.

If the inferred body size difference between the archaeological and modern $P$. verreauxi samples does reflect an evolutionary process in response to human size-selective hunting behavior, then it is of interest to compare the estimated rate of that evolutionary change to previously observations for other archaeological cases of this phenomenon. We estimated an evolutionary rate of 156 darwins, or the magnitude of morphological change (absolute value of the difference between the natural log of the starting trait value and the natural log of the ending trait value) per million years [51] using our data from the right femur width of lateral distal condyle $(\mathrm{n}=4$ subfossil individuals, mean width=7.76 $\mathrm{mm}$, average 771 cal. years BP, calculated with midpoints of $95.4 \% \mathrm{Cl}$ cal. years BP; $n=23$ modern individuals, mean width $=6.88 \mathrm{~mm}$ ). Using these values along with the $P$. verreauxi cohort generation time (average between the birth of a female and the birth of her daughters) of 18.5 years [52,53], we also estimated a Haldane $(H)$ evolutionary rate of $-0.039 \mathrm{H}$, which represents the rate of change in standard deviations per generation [54]. While $H$ is likely a more meaningful statistic, only darwin estimates are available for direct comparison with other taxa. Compared to seven previously-analyzed archaeological examples of purported morphological change in response to human behavior (darwin mean=21.4; range $=1-72$; [1] the rate of 156 darwins for $P$. verreauxi is at least $\sim 2 x$ and an average of $7.3 x$ greater. 


\section{ACKNOWLEDGMENTS}

We thank the Madagascar National Parks organization and our colleagues at the Beza Mahafaly Special Reserve, including Joel Ratsirarson, Jeannin Ranaivonasy, Sibien Mahereza, Elaine Guevara, Brenda Bradley, Roshna Wunderlich, and Alison Richard. We also thank the University of Massachusetts Amherst Natural History Collections for allowing access to the Taolambiby collection, and Lily Doershuk for her advice on working with 3D data. We would like to acknowledge support from the Peter A. and Marion W. Schwartz Family Foundation for providing funds (to L.R.G.) to help build the Beza Mahafaly Osteological Collection. This project was supported by National Science Foundation grant BCS-1554834 (to G.H.P.), the National Science Foundation grant BCS-1750598 (to L.R.G.), and the National Science Foundation Graduate Research Fellowship Program (DGE1255832, to A.P.S.). Any opinions, findings, and conclusions or recommendations expressed in this material are those of the authors and do not necessarily reflect the views of the National Science Foundation.

\section{SUPPLEMENTARY MATERIALS}

Supplemental Database: MorphoSource repository of Artec Space Spider 3D surface scan data (.ply models) for all modern and subfossil Propithecus verreauxi individuals (https://www.morphosource.org/Detail/ProjectDetail/Show/project id/698)

Supplemental Table 1: List of modern Beza Mahafaly Propithecus verreauxi individuals and measured long bones (femur, humerus)

Supplemental Table 2: Modern and subfossil Propithecus verreauxi radial caliper measurements and fold-changes

Supplemental Table 3: Modern and subfossil Propithecus verreauxi 3D scan Avizo measurements and fold-changes

Supplemental Table 4: Average percent differences between radial caliper and 3D model measurements Supplemental Table 5: Radial caliper versus 3D scan Avizo measurements

Supplemental Table 6: Aggregate scores for all modern and subfossil Propithecus verreauxi individuals

\section{REFERENCES}

1. Sullivan AP, Bird DW, Perry GH. 2017 Human behaviour as a long-term ecological driver of nonhuman evolution. Nat. Ecol. Evol. 1, 0065. (doi:10.1038/s41559-016-0065)

2. Fenberg PB, Roy K. 2008 Ecological and evolutionary consequences of size-selective harvesting: how much do we know? Mol. Ecol. 17, 209-220. (doi:10.1111/j.1365-294X.2007.03522.x)

3. Darimont CT, Carlson SM, Kinnison MT, Paquet PC, Reimchen TE, Wilmers CC. 2009 Human predators outpace other agents of trait change in the wild: Fig. 1. Proc. Natl. Acad. Sci. 106, 952954. (doi:10.1073/pnas.0809235106)

4. O'Dea A, Shaffer ML, Doughty DR, Wake T a, Rodriguez F a. 2014 Evidence of size-selective evolution in the fighting conch from prehistoric subsistence harvesting. Proc. R. Soc. B Biol. Sci. 281, 20140159. (doi:10.1098/rspb.2014.0159)

5. Roy K, Collins AG, Becker BJ, Begovic E, Engle JM. 2003 Anthropogenic impacts and historical decline in body size of rocky intertidal gastropods in southern California. Ecol. Lett. 6, 205-211. (doi:10.1046/j.1461-0248.2003.00419.x)

6. Allendorf FW, Hard JJ. 2009 Human-induced evolution caused by unnatural selection through harvest of wild animals. Proc. Natl. Acad. Sci. 106, 9987-9994. (doi:10.1073/pnas.0901069106)

7. Ricker WE. 1981 Changes in the Average Size and Average Age of Pacific Salmon. Can. J. Fish. Aquat. Sci. 38, 1636-1656. (doi:10.1139/f81-213)

8. Pelletier F, Festa-Bianchet M, Jorgenson JT. 2012 Data from selective harvests underestimate temporal trends in quantitative traits. Biol. Lett. 8, 878-881. (doi:10.1098/rsbl.2011.1207) 
9. Coltman DW, O’Donoghue P, Jorgenson JT, Hogg JT, Strobeck C, Festa-Bianchet M. 2003 Undesirable evolutionary consequences of trophy hunting. Nature 426, 655-658. (doi:10.1038/nature02177)

10. Hansford JP, Turvey ST. 2018 Unexpected diversity within the extinct elephant birds (Aves: Aepyornithidae) and a new identity for the world's largest bird. R. Soc. Open Sci. 5, 181295. (doi:10.1098/rsos.181295)

11. Godfrey LR, Jungers WL. 2003 The extinct sloth lemurs of Madagascar. Evol. Anthropol. Issues, News, Rev. 12, 252-263. (doi:10.1002/evan.10123)

12. Jungers WL, Demes B, Godfrey LR. 2008 How Big were the "Giant" Extinct Lemurs of Madagascar? In Elwyn Simons: A Search for Origins, pp. 343-360. New York, NY: Springer New York. (doi:10.1007/978-0-387-73896-3_23)

13. Dewar RE, Radimilahy C, Wright HT, Jacobs Z, Kelly GO, Berna F. 2013 Stone tools and foraging in northern Madagascar challenge Holocene extinction models. Proc. Natl. Acad. Sci. 110, 1258312588. (doi:10.1073/pnas.1306100110)

14. Anderson A et al. 2018 New evidence of megafaunal bone damage indicates late colonization of Madagascar. PLoS One 13, e0204368. (doi:10.1371/journal.pone.0204368)

15. Douglass K, Hixon S, Wright HT, Godfrey LR, Crowley BE, Manjakahery B, Rasolondrainy T, Crossland Z, Radimilahy C. 2019 A critical review of radiocarbon dates clarifies the human settlement of Madagascar. Quat. Sci. Rev. 221, 105878. (doi:10.1016/j.quascirev.2019.105878)

16. Hansford J, Wright PC, Rasoamiaramanana A, Pérez VR, Godfrey LR, Errickson D, Thompson T, Turvey ST. 2018 Early Holocene human presence in Madagascar evidenced by exploitation of avian megafauna. Sci. Adv. 4, eaat6925. (doi:10.1126/sciadv.aat6925)

17. Godfrey LR, Scroxton N, Crowley BE, Burns SJ, Sutherland MR, Pérez VR, Faina P, McGee D, Ranivoharimanana L. 2019 A new interpretation of Madagascar's megafaunal decline: The "Subsistence Shift Hypothesis". J. Hum. Evol. 130, 126-140. (doi:10.1016/j.jhevol.2019.03.002)

18. Burney DA, Burney LP, Godfrey LR, Jungers WL, Goodman SM, Wright HT, Jull AJT. 2004 A chronology for late prehistoric Madagascar. J. Hum. Evol. 47, 25-63.

(doi:10.1016/j.jhevol.2004.05.005)

19. Perez VR, Godfrey LR, Nowak-Kemp M, Burney DA, Ratsimbazafy J, Vasey N. 2005 Evidence of early butchery of giant lemurs in Madagascar. J. Hum. Evol. 49, 722-742.

(doi:10.1016/j.jhevol.2005.08.004)

20. Dewar RE. 1984 Extinctions in Madagascar: the loss of the subfossil fauna. In Quaternary Extinctions (eds P Martin, R Klein), pp. 574-593. Tucson: University of Arizona Press,.

21. Hixon SW, Elliott Smith EA, Crowley BE, Perry GH, Randrianasy J, Ranaivoarisoa JF, Kennett DJ, Newsome SD. 2018 Nitrogen isotope $(\delta 15 N)$ patterns for amino acids in lemur bones are inconsistent with aridity driving megafaunal extinction in south-western Madagascar. J. Quat. Sci. 33, 958-968. (doi:10.1002/jqs.3073)

22. Kistler L et al. 2015 Comparative and population mitogenomic analyses of Madagascar's extinct, giant 'subfossil' lemurs. J. Hum. Evol. 79, 45-54. (doi:10.1016/j.jhevol.2014.06.016)

23. Godfrey LR, Irwin MT. 2007 The Evolution of Extinction Risk: Past and Present Anthropogenic Impacts on the Primate Communities of Madagascar. Folia Primatol. 78, 405-419. (doi:10.1159/000105152)

24. Crowley BE. 2010 A refined chronology of prehistoric Madagascar and the demise of the megafauna. Quat. Sci. Rev. 29, 2591-2603. (doi:10.1016/j.quascirev.2010.06.030)

25. Muldoon KM, Simons EL. 2007 Ecogeographic size variation in small-bodied subfossil primates from Ankilitelo, Southwestern Madagascar. Am. J. Phys. Anthropol. 134, 152-161. (doi:10.1002/ajpa.20651)

26. Godfrey LR, Jungers WL, Simons EL, Chatrath PS, Rakotosamimanana B. 1999 Past and Present 
Distributions of Lemurs in Madagascar. In New Directions in Lemur Studies (eds B Rakotosamimanana, H Rasamimanana, JU Ganzhorn, SM Goodman), pp. 19-53. Boston, MA: Springer US. (doi:10.1007/978-1-4615-4705-1_2)

27. Albrecht GH, Jenkins PD, Godfrey LR. 1990 Ecogeographic size variation among the living and subfossil prosimians of Madagascar. Am. J. Primatol. 22, 1-50. (doi:10.1002/ajp.1350220102)

28. Lamberton C. 1939 Contribution à la connaissance de la faune subfossile de Madagascar. Lémuriens et cryptoproctes. Note IV. Nouveaux lémuriens fossiles du groupe des Propithèques. Mémoires de l'Académie Malgache 27, 9-49.

29. Richard AF, Dewar RE, Schwartz M, Ratsirarson J. 2000 Mass change, environmental variability and female fertility in wild Propithecus verreauxi. J. Hum. Evol. 39, 381-391.

(doi:10.1006/jhev.2000.0427)

30. Richard AF, Dewar RE, Schwartz M, Ratsirarson J. 2006 Life in the slow lane? Demography and life histories of male and female sifaka (Propithecus verreauxi verreauxi). J. Zool. 256, 421-436. (doi:10.1017/S0952836902000468)

31. Razafimanahaka JH, Jenkins RKB, Andriafidison D, Randrianandrianina F, Rakotomboavonjy V, Keane A, Jones JPG. 2012 Novel approach for quantifying illegal bushmeat consumption reveals high consumption of protected species in Madagascar. Oryx 46, 584-592.

(doi:10.1017/S0030605312000579)

32. Randrianandrianina FH, Racey P a., Jenkins RKB. 2010 Hunting and consumption of mammals and birds by people in urban areas of western Madagascar. Oryx 44, 411-415.

(doi:10.1017/S003060531000044X)

33. Gardner CJ, Davies ZG. 2014 Rural Bushmeat Consumption Within Multiple-use Protected Areas: Qualitative Evidence from Southwest Madagascar. Hum. Ecol. 42, 21-34. (doi:10.1007/s10745013-9629-1)

34. Sussman RW, Richard AF, Ratsirarson J, Sauther ML, Brockman DK, Gould L, Lawler R, Cuozzo FP. 2012 Beza Mahafaly Special Reserve: Long-Term Research on Lemurs in Southwestern Madagascar. In Long-Term Field Studies of Primates (eds PM Kappeler, DP Watts), pp. 45-66. Berlin, Heidelberg: Springer Berlin Heidelberg. (doi:10.1007/978-3-642-22514-7_3)

35. Brockman DK, Godfrey LR, Dollar L, Ratsirarson J. 2008 Evidence of Invasive Felis silvestris Predation on Propithecus verreauxi at Beza Mahafaly Special Reserve, Madagascar. Int. J. Primatol. 29, 135-152. (doi:10.1007/s10764-007-9145-5)

36. Godfrey LR, Sutherland MR, Paine RR, Williams FL, Boy DS, Vuillaume-Randriamanantena M. 1995 Limb joint surface areas and their ratios in Malagasy lemurs and other mammals. Am. J. Phys. Anthropol. 97, 11-36. (doi:10.1002/ajpa.1330970103)

37. Egi N. 2001 Body Mass Estimates in Extinct Mammals from Limb Bone Dimensions: the Case of North American Hyaenodontids. Palaeontology 44, 497-528. (doi:10.1111/1475-4983.00189)

38. Jenkins PD, Albrecht GH. 1991 Sexual dimorphism and sex ratios in Madagascan prosimians. Am. J. Primatol. 24, 1-14. (doi:10.1002/ajp.1350240102)

39. Kappeler PM. 1991 Patterns of Sexual Dimorphism in Body Weight among Prosimian Primates. Folia Primatol. 57, 132-146. (doi:10.1159/000156575)

40. Lawler RR. 2009 Monomorphism, male-male competition, and mechanisms of sexual dimorphism. J. Hum. Evol. 57, 321-325. (doi:10.1016/j.jhevol.2009.07.001)

41. White TD, Black MT, Folkens PA. 2012 Human Osteology. 3rd edn.

42. Crowley BE, Godfrey LR. 2013 Why all those spines? Anachronistic defences in the Didiereoideae against now extinct lemurs. S. Afr. J. Sci. 109, 1-7. (doi:10.1590/sajs.2013/1346)

43. Stafford TW, Brendel K, Duhamel RC. 1988 Radiocarbon, $13 C$ and $15 \mathrm{~N}$ analysis of fossil bone: Removal of humates with XAD-2 resin. Geochim. Cosmochim. Acta 52, 2257-2267. (doi:10.1016/0016-7037(88)90128-7) 
44. Stafford TW, Hare PE, Currie L, Jull AJT, Donahue DJ. 1991 Accelerator radiocarbon dating at the molecular level. J. Archaeol. Sci. 18, 35-72. (doi:10.1016/0305-4403(91)90078-4)

45. Bronk Ramsey C. 2009 Bayesian Analysis of Radiocarbon Dates. Radiocarbon 51, 337-360. (doi:10.1017/S0033822200033865)

46. Hogg AG et al. 2013 SHCal13 Southern Hemisphere Calibration, 0-50,000 Years cal BP. Radiocarbon 55, 1889-1903. (doi:10.2458/azu_js_rc.55.16783)

47. Gordon AD, Green DJ, Richmond BG. 2008 Strong postcranial size dimorphism in Australopithecus afarensis: Results from two new resampling methods for multivariate data sets with missing data. Am. J. Phys. Anthropol. 135, 311-328. (doi:10.1002/ajpa.20745)

48. Miller JH, Behrensmeyer AK, Du A, Lyons SK, Patterson D, Tóth A, Villaseñor A, Kanga E, Reed D. 2014 Ecological fidelity of functional traits based on species presence-absence in a modern mammalian bone assemblage (Amboseli, Kenya). Paleobiology 40, 560-583. (doi:10.1666/13062)

49. Dunham AE, Erhart EM, Overdorff DJ, Wright PC. 2008 Evaluating effects of deforestation, hunting, and El Niño events on a threatened lemur. Biol. Conserv. 141, 287-297.

(doi:10.1016/j.biocon.2007.10.006)

50. Lehman SH, Ratsimbazafy RH. 2001 Biological assessment of the Fandriana-Marolambo forest corridor, Madagascar. Lemur News 6, 8.

51. Haldane JBS. 1949 Suggestions as to Quantitative Measurement of Rates of Evolution. Evolution 3, 51. (doi:10.2307/2405451)

52. Morris WF et al. 2011 Low Demographic Variability in Wild Primate Populations: Fitness Impacts of Variation, Covariation, and Serial Correlation in Vital Rates. Am. Nat. 177, E14-E28. (doi:10.1086/657443)

53. Lawler RR, Caswell H, Richard AF, Ratsirarson J, Dewar RE, Schwartz M. 2009 Demography of Verreaux's sifaka in a stochastic rainfall environment. Oecologia 161, 491-504.

(doi:10.1007/s00442-009-1382-1)

54. Gingerich PD. 1993 Quantification and comparison of evolutionary rates. Am. J. Sci. 293, 453478. (doi:10.2475/ajs.293.A.453) 